This item was submitted to Loughborough's Research Repository by the author.

Items in Figshare are protected by copyright, with all rights reserved, unless otherwise indicated.

\title{
What if best practice is too expensive? Feedback on oral presentations and efficient use of resources
}

PLEASE CITE THE PUBLISHED VERSION

http://dx.doi.org/10.1080/02602938.2015.1109054

\section{PUBLISHER}

(c) Taylor \& Francis

\section{VERSION}

AM (Accepted Manuscript)

\section{PUBLISHER STATEMENT}

This work is made available according to the conditions of the Creative Commons Attribution-NonCommercialNoDerivatives 4.0 International (CC BY-NC-ND 4.0) licence. Full details of this licence are available at: https://creativecommons.org/licenses/by-nc-nd/4.0/

\section{LICENCE}

CC BY-NC-ND 4.0

\section{REPOSITORY RECORD}

Leger, Lawrence A., Karligash Glass, Paraskevi Katsiampa, Shibo Liu, and Kavita Sirichand. 2019. "What If Best Practice Is Too Expensive? Feedback on Oral Presentations and Efficient Use of Resources". figshare. https://hdl.handle.net/2134/19757. 


\title{
What if Best Practice is Too Expensive? Feedback on Oral Presentations and Efficient Use of Resources
}

\author{
Lawrence A. Leger*a, Karligash Glass ${ }^{\mathrm{a}}$, Paraskevi Katsiampab, Shibo Liuª, \\ Kavita Sirichand ${ }^{\mathrm{a}}$ \\ a School of Business and Economics, Loughborough University, Loughborough, UK \\ $b$ Sheffield Hallam University, Sheffield, UK
}

\begin{abstract}
We evaluate feedback methods for oral presentations used in training nonquantitative research skills (literature review and various associated tasks). Training is provided through a credit-bearing module taught to MSc students of banking, economics and finance in the UK. Monitoring oral presentations and providing 'best practice' feedback is very resource-intensive. Do we withdraw oral presentations from the module, because best feedback practice is prohibitively expensive in a world of limited resources, or choose a second-best alternative? To what extent might the latter compromise intended learning outcomes? We used the same provision of video feedback for all students but used two verbal feedback regimes. For one regime we decreased the amount of verbal feedback and increased the number of presentations. The impact was measured by academic outcome, rating scales and questionnaire. Overall satisfaction with the module was very high for both feedback regimes, and there were no statistically significant differences between regimes, suggesting that less resource-intensive methods need not compromise learning outcomes.
\end{abstract}

Keywords: feedback, oral presentations, video feedback, limited resources, skills training

* Corresponding author. Email: l.a.leger@lboro.ac.uk 


\section{Introduction}

This paper evaluates methods of providing formative feedback on oral presentations when teaching resources are limited. The context is a credit-bearing classroom module in which students are trained in literature review and various associated skills, in preparation for the research component of an MSc degree at Loughborough University (UK). The MSc research component consists of either a dissertation or structured research practice assessed by written examination. In preparation for this, the module targets skills in literature search, analysis of papers, citation and referencing, review by critical constructive synthesis, formulation of research proposals, and communication in general. It involves, inter alia, four sets of oral presentations made by students during one semester, with feedback that is immediate (verbal) and delayed (online video), and intended to promote both self-evaluation and comparison against external criteria. It may be important that most of our MSc students are Chinese, but we have found few differences between students of different nationalities (UK included) with respect to either literature review skills in general or oral presentation skills in particular. This paper extends a description by Leger and Sirichand (2015) of the basic form, rationale and development of the module by reporting on a comparison of two feedback regimes.

It seems unlikely that a single 'best practice' form of feedback could ever be identified, since this would inevitably vary across different learning situations, but there do seem to be some recognised conditions for effective feedback (Gibbs and Simpson, 2004). For non-assessed oral presentations in particular, we start from the premise that effective feedback should involve peer- and tutor- feedback, with opportunities for extensive in-class discussion and self-reflection. It should be face-to-face (one-to-one where appropriate), clearly targeted, engaging for students and student-centred but authoritative where necessary (from highly-experienced tutors).

Providing such feedback is very resource-intensive, so we compared learning outcomes for two 'second best' formative feedback regimes of different resourceintensity - video plus summary verbal feedback vs. video plus extended verbal feedback. The summary and extended feedback took about one minute and five minutes respectively. We asked students to evaluate their feedback regimes via a questionnaire, because we were concerned that brief feedback might reduce students' motivation for learning in the context of our module. 
Our results suggest that learning outcomes need not be compromised by more efficient use of resources and they raise interesting issues about students' perceptions of feedback and how it might be delivered. The paper also adds to the literature on the active learning of skills in oral presentation and literature review.

In the remaining sections we outline the essential features of feedback in the module and justify the particular comparison under review. We describe the nature and purpose of the oral presentations, the feedback methods and students' evaluations, and we provide an analysis of outcomes.

\section{Issues in Feedback}

The module (Leger and Sirichand, 2015) providing the context for this paper has been designed with reference to theories of learning and instructional design (Kolb, 1984; Bandura, 1986; Mager, 1991; McLeod, 2003; Tennyson, 2010), constructive alignment (Biggs and Tang, 2011) and active learning (Machemer and Crawford, 2007), and it is intended to encourage ‘deep learning' (Entwistle and McCune, 2009). The cycle of learning in the module involves explanations of tasks with demonstrations of oral presentations by a tutor, followed by planning and preparation by the students, leading to performance, feedback (with discussion and self-reflection) and repeated practice, which is a process akin to Zimmerman's cyclical three stages of self-regulated learning (Zimmerman, 2005; Zimmerman and Moylan, 2009).

Feedback in the module is informed by discussions of self-regulated learning (Butler and Winne, 1995; Cassidy, 2011; Zimmerman and Schunk, 2011), student motivation (Hattie and Timperly, 2007; Hoskins and Newstead, 2009; Price et al. 2010) and the use of video (Fukkink et al., 2011; Murphy and Barry, 2015). It is also influenced by concepts of formative assessment both in general (Higgins et al., 2002; Shute, 2008; Scaife and Wellington, 2010) and in self-regulated learning (Nicol and Macfarlane-Dick, 2006; Beaumont et al., 2011; Clark, 2012). The literature also discusses the need for students to acquire concepts by which to understand feedback on assessed work, possibly learning these through dialogue and peer-assessment (Beaumont et al., 2011; Sadler, 2010) and, while we not concerned with assessed work in this paper, elements of peer-assessment and dialogue are present in our procedures.

We believe that feedback should both help students to generate principles for use in future learning and allow generalisation of skills to other contexts. In other 
words, feedback should be forward-looking and developmental (Higgins et al., 2001; Gibbs and Simpson, 2004; Beaumont et al., 2011) and have measurable and sustainable impact on learning (Carless et al., 2011; Boud and Molloy, 2013). To summarise, feedback should foster self-regulation and provide external standards against which self-reflection can be benchmarked.

Three general issues in feedback are particularly important here. First, Hattie and Timperly (2007) assert that the information content is what matters, regardless of context. They assert that person-directed feedback (evaluation amounting to reward or punishment) has limited or zero value in the absence of useful information. Second, Price et al. (2010) caution that feedback needs to be quite complex if it is to match the multi-dimensional character of assessment and hence risks being not only poorly defined and measured but also poorly understood, or even unrecognised, by students. It is argued by Sadler (2010) and Beaumont et al. (2011), for example, that bringing students into the feedback process may alleviate the latter problems. This implies a need for structure, clarity and focus in the design of feedback that becomes even more important when resource constraints are binding. Third, it is recognised that motivation is as important as feedback - simply stated, even excellent feedback will not promote learning in disengaged students.

Hoskins and Newstead (2009) note that motivation for university education corresponds to the concepts of 'intrinsic' and 'extrinsic' motivation in psychology and education (Ryan and Deci, 2000; Brockbank and McGill, 2007). They add that the ‘amotivation’ of Ryan and Deci may be a dimension of motivational strength, and suggest that it can be alleviated by active engagement. These concepts can be further linked to the 'surface', 'deep' and 'strategic' styles found in the 'approaches to learning' framework (Entwistle and McCune, 2009). Summarising from Sloman and Mitchell (2013), 'surface’ learning may follow from heavy work-load, poor feedback, emphasis on rote learning and assessment, and lack of student independence, possibly accompanied by anxiety and withdrawal of interest. 'Deep' learning allows students to form a conceptual overview of a subject and is facilitated by active involvement. ‘Strategic’ learning implies behaviour intended to maximise grades.

Our intention has been to encourage deep learning, for various reasons. First, the module has a 'domain-specific' content (Tennyson, 2010) in that literature review and associated skills should be transferable to any research field. Second, it should help 
graduates into employment - a goal of both employers and government. Third, it should help promote self-confidence in any aspect of daily life involving communication and problem-solving. In each case, we believe that transferability is best promoted by acquiring generalised conceptual principles for the formulation and analysis of problems, and by developing generalised skills in communication - that is, by deep learning.

Little seems to have been written on maximising feedback effectiveness when resources are limited. There has been discussion of online digital media and blended learning methods to relieve constraints on limited resources in the classroom (Garrison and Vaughan, 2008; Njenga and Fourie, 2010) and of methods to save resources in written feedback on assessed work (see Sadler, 2010) but this has not addressed classroom feedback on oral presentations.

Our students pay high fees, have high workloads and want face-to-face feedback from experienced tutors. There is a subtle problem here. Student-centred approaches involving self-regulation and active learning may promote deep learning and high generalisation of outcomes but skills acquisition seems to require at least some degree of authoritative feedback. The question is how to provide the latter as efficiently as possible without diverting learners from the former.

Our compromise is to provide tutor feedback on structured tasks, using both immediate verbal and delayed video feedback, within a framework in which students make decisions about how they organise their presentations and use the feedback provided. We regard video feedback as desirable because of its potential value in engaging students and promoting generalised learning (Murphy and Barry, 2015). Evidence from the review and meta-analysis of Fukkink et al. (2011) suggests that significant gains can be made from using video when training professionals in interaction and communication skills. Observing themselves on video should help students in their self-reflection, thereby reducing the amount of verbal feedback needed and relieving time constraints in the classroom. The feedback regimes were therefore designed in the knowledge that video feedback would also be available.

\section{Comparing Feedback Methods}

If self-regulated learning is more effective than instruction, students who self-reflect when reviewing video recordings may develop good skills irrespective of the amount of 
verbal feedback they receive. Moreover, if the impact of the latter depends on the quality of the information provided (Hattie and Timperly, 2007; Price et al., 2010) it may be that important elements can be delivered very quickly. Reducing time spent on verbal feedback and increasing the number of student presentations per tutorial might therefore lead to substantial resource savings without compromising learning outcomes.

We compare two feedback regimes with identical video feedback provision but different intensity of resource-use: (i) summary verbal feedback (one minute) with four presentations per tutorial and (ii) extended verbal feedback (five minutes) with three presentations per tutorial. While the difference between one minute and five minutes of feedback may not seem large, the perceived difference in the class-room is actually quite substantial and we are quite comfortable that the regimes were truly distinct. We emphasise that the impact of immediate verbal feedback in both regimes is dependent on use of the video feedback provided and it is not appropriate to generalise our results to situations where video feedback is absent.

\section{Essential Features of the Module}

\section{Intended learning outcomes}

The intended learning outcomes of the module are that students should be able to: (i) understand what is meant by plagiarism and poor scholarship and know how to avoid these; (ii) use a structured literature search to select articles on any topic, analyse selected articles and construct a conceptual framework through which to understand them; (iii) write critical thematic reviews by constructive synthesis of any technically accessible literature; (iv) formulate research questions and write proposals for future research; (v) make clear succinct presentations, both oral and written; (vi) show preparatory knowledge of a specialist research topic (for later research training) and (vii) show transferable skills relevant to employment and daily life.

In this paper we focus specifically on evaluating the impact of different feedback regimes for promoting the development of skills in communication and competence in specific tasks related to literature review. 


\section{Tutorial tasks}

The subject matter for oral presentations was presented in lectures, based on two reading sets. Each set consisted of six carefully-edited papers on a particular theme. The tasks involved both individual work (reading the articles and summarising them) and group work (shown in Table 1). Timetabled but unsupervised preparation (about 115 minutes) was followed immediately by tutorial presentations. Depending on feedback regime, either three or four 12-minute presentations were made in each of four 55-minute tutorials. Students were also expected to work prior to the scheduled times, to establish the necessary foundations for the tasks. The organisation of presentations was decided by the work groups themselves - while most students gave individual presentations, in a very few cases two or three students would present sequentially within the 12 minutes allowed. Students had only a whiteboard as visual aid, forcing strict focus on the essentials needed to present well-structured, simple, clear and succinct solutions to the tasks. The primary aim of the module is to encourage the active learning of literature review skills, rather than oral presentation skills per se, so the 12 minute limit was set after experimenting with the minimum time needed for the tasks to be presented satisfactorily. The total time for feedback was therefore the residual tutorial time, even though longer time for feedback might be desirable, because extra time for practice was deemed more important overall in the context of the intended learning outcomes.

\section{Insert Table 1 about here}

\section{Feedback methods}

We used a mixture of self-, peer- and tutor-assessment, with feedback on 'content' and 'style'. Content feedback covered conceptual clarity (succinctness, accuracy of summary, degree of synthesis) and task outcome (selection of material, degree of completion, overall structure of presentation). Style feedback focused on the manner of presentation, including audience engagement (eye-contact, interaction with and responsiveness to the audience, body language), clarity (legibility of writing, use of whiteboard, clarity of speech), speed of delivery and time-management. The criteria for verbal feedback were similar to those used in written feedback on the assessed oral presentation undertaken at the end of the first semester (as shown in Table 2) but with task-specific features. The feedback criteria for the assessed presentation include elements specific to proposals for new empirical research, so these were appropriate for 
tutorial 4 (reading set 2) but had to be modified for bullet-point summaries, spider diagrams and outline literature review.

For self-assessment, students were asked to comment on their own performance immediately after their presentations, to view their online videos and to reflect on ways of achieving their goals more effectively. A complete video of every presentation was made privately available online. Feedback consisted of requiring students to watch these videos and reflect on their performance, but students were not required to report their self-reflections.

Students were also asked to make hand-written notes when observing the presentations of others, to promote active engagement and the discovery of better techniques. We take the view that observation without note-taking is likely to encourage passivity and inattention but that active, critical and self-reflective note-taking should encourage self-regulation. In peer-assessment, we asked for non-judgemental constructive comments from the audience on how a presentation could be specifically improved in content and/or style and on the ease of note-taking.

We have found that students like feedback that evaluates performance in a 'realworld' sense, so the immediate verbal feedback assumed that presenters were also being interviewed for work. They were told (not verbatim) whether or not they 'got the job' (task achieved), 'were invited for the next round of interviews', 'failed to progress on this occasion but were encouraged to apply again', or ‘did not get the job’ (task not achieved). This benchmarked other comments on specific aspects of content and style, addressed the element of transferability to employment in the intended learning outcomes and seemed to motivate student engagement.

To summarise, feedback was focused on both content and style and was given verbally, by online video and indirectly through observation of presentations made by others. It was intended to be formative and to promote student control over learning.

\section{Experimental Design for Evaluation of Feedback Methods}

\section{Feedback regimes}

Video recordings were posted online within six hours of each tutorial. Individuals could view their own videos and those of others in their work group, but not those of other 
groups. Verbal feedback was given immediately after each oral presentation. This was either summary (S) or extended (E) and was focused on content and style.

Summary (S): Four 12-minute presentations each followed by approximately one minute of tutor feedback.

Extended $(E)$ : Three 12-minute presentations each followed by approximately five minutes of self-, peer- and tutor feedback.

Various controls were used to mitigate any potential differences between groups other than those implied by the feedback regime.

1. Two tutors were rotated across groups in a balanced way over the tutorial schedule.

2. As far as possible, given timetable constraints, equal numbers of students were allocated to regimes, tutorials and work-groups.

3. Students were otherwise randomly assigned, with post-allocation checks on balancing with respect to 'learning potential' and post-module checks on the extent to which students participated by viewing their videos. Learning potential was rated from 1 (highest) to 5 and was assessed by English ability (IELTS score or equivalent), quality of undergraduate institution, based on Netbig ${ }^{\mathrm{TM}}$ and NARIC ${ }^{\mathrm{TM}}$ rankings, and undergraduate grades. Netbig (http://rank2011.netbig.com/en/) is a Chinese web site that provides ranks for most universities in China. UK NARIC (https://www.naric.org.uk/naric/) is a national agency providing information and opinion on vocational, academic and professional qualifications from across the world.

4. All but 4 students were randomly assigned to one of ten dedicated English language classes, subject to timetable constraints. This allocation turned out to be unenforceable but there was no evidence that this actually mattered.

\section{Participants}

Participants were 96 MSc students, the vast majority (95\%) from P.R. China (reflecting a demographic now familiar in UK universities). The MSc entry requirement was an upper second class honours degree or international equivalent (judged from Netbig ${ }^{\mathrm{TM}}$ rankings for China and NARICTM for other countries.

The average standard of English language satisfied the University's requirement of 6.5 IELTS with individual scores no less than 6.0, or 6.0 IELTS with five- or ten- 
week pre-sessional language classes. In addition, all students with IELTS scores less than 7.5 took the dedicated language class (syllabus available on request).

\section{Ethical issues in the pedagogical treatment of participants}

The regimes were designed with the approval of the teaching quality unit of the University so that neither had an obvious pedagogic advantage. For summary feedback (a potential disadvantage compared to extensive feedback) the regime was therefore strengthened by extra presentations (more observation and practice). Students could withdraw from the evaluative process but they were neither allowed to withdraw from the module itself nor given the choice of regime.

\section{Evaluation of feedback effectiveness}

Differences in academic performance were assessed through marks for this module and overall marks for all other MSc modules. Perceptions of the effectiveness of feedback were measured through post-module questionnaires, using both 5-point Likert scales and open-ended questionnaire items. The open-ended items were

1. What did you learn from the feedback (verbal or video) you received after your tutorial presentations in semester 1 ?

2. What did you learn from the tutorial presentations in semester 1 ?

3. Please comment on the Research Communication module in any way you want.

4. What did you learn from the module?

5. In what ways could the Research Communication module be improved?

6. What is the best way to receive feedback on your tutorial presentations?

7. What skills, if any, have you learned in the Research Communication module that can be applied in other situations?

8. Please add any further comments you wish to make.

The overlap in questions was deliberate, to elicit as many responses as possible.

The questionnaires were labelled $E$ or $S$, allowing regime average responses to be identified, but were otherwise anonymous. The rating scale responses were amenable to direct statistical evaluation but the open-ended responses required response-coding prior to analysis. 


\section{Rating scales}

Average scores for rating scale items were compared across regimes, and differences were tested for statistical significance. Simple reliability checks were carried out, to control for careless or random responding by participants: (i) opposite wording was used for two pairs of otherwise similar items, effectively reversing the scoring from 'agree-disagree’ to ‘disagree-agree’ and (ii) two pairs of identical or very similar items were included that could reasonably be expected to elicit the same response. A 'discrepancy score' was then calculated from the difference in the observed ratings for each pair (oppositely-worded pairs were first re-aligned), giving a maximum total discrepancy score of 16 for all four pairs. Respondents with discrepancy scores greater than 8 were to be removed from the analysis.

Analysis of group means for rating scale responses could also be biased by differences in response 'style', such as extreme or central responding, or identical responses to all items ('halo’ effects). Response styles should appear in the standard deviations of responses by individuals so regime differences in these styles were tested by comparing the distributions and means of standard deviations across regimes.

\section{Open-ended items}

The responses to open-ended items were subjected to content analysis with subsequent statistical evaluation. Many categorisations can be extracted from open-ended data, but we focused on the overall effectiveness of the module in delivering its intended outcomes, with special attention to feedback methods.

Categories were formed by finding response similarities across individuals and grouping these at high levels of generality. To control for subjective bias, appropriate categories and category elements were identified by a preliminary analysis and the questionnaire responses were re-coded by two independent assessors. The following guidelines were used: (i) similar responses made to more than one question were counted as a single response and assigned to the most appropriate category; (ii) multiple responses within a single element were counted as a single response to that element, revealing the total number of individuals responding to an element rather than the number of different ways of responding to it, and (iii) a response was assigned to only one category and only one element within that category. 


\section{Hypotheses}

The main aim was to discover whether increased efficiency in module delivery would lead to a reduction in academic effectiveness. Since the regimes were intended to be equally effective, this led to a null hypothesis for academic attainment:

Hypothesis 1. Average grades are equal for the two regimes, both for the module under analysis and taught modules overall.

Students' views about video feedback were not well known at the date of the questionnaire because this medium had been only recently introduced but, from informal communication over several years, it appeared that students liked to receive immediate verbal feedback and the more of it the better. Hence, while the analysis was mainly exploratory, a general null hypothesis on preferences was suggested:

Hypothesis 2. Students in both regimes show no preferences for verbal or video feedback, in either rating scale items or open-ended items.

Alternative Hypothesis. Students in both regimes show an absolute preference for verbal feedback, with no differences between regimes

\section{Results}

93 of the 96 participants completed feedback questionnaires, 45 for regime $S$ and 48 for regime $E$, providing responses on both rating scales and open-ended items. Leger and Sirichand (2015) provide full details of the aggregated responses - here we extend that analysis by comparing responses across feedback regimes and evaluating the comparative results for an 'overall evaluation' category and categories specific to feedback.

\section{Controls for learning potential and video viewing}

The 'learning potential' scores were 3.17 and 3.5 for regimes $S$ and $E$ respectively. Although the difference is perhaps larger than desirable, it is non-significant $(t=1.32$, p-value $=0.41$, two-tailed), so we conclude that outcomes were not affected.

Students could download their videos, so an exact count of viewings was impossible. However, of respondents who completed the questionnaire, over 92\% (86 out of 93) claimed to have watched the videos of their own group's presentations, with a very large majority indicating that video feedback was important in helping them to 
identify ways to improve their presentation style (31 'strongly agree' and 45 'agree' in rating scale responses).

There is evidence of repeated video viewing: $87 \%$ of respondents claimed to have viewed their own presentations up to 3 times, and 6.4\% either 4 or 5 times. Only $6.5 \%$ claimed never to have viewed their own videos at all. $1 \%$ did not respond. They were also asked to report their viewings of video presentations by other group members. The results here are similar, but with a higher percentage claiming not to have viewed at all (81.7\%, $4.3 \%$ and $13.8 \%$ respectively).

There is no significant difference for numbers of claimed viewings, either for own presentations $(t=-0.795$, p-value $=0.57)$ or others $(t=0.055$, p-value $=0.97)$, suggesting that results were not distorted by regime differences in video usage.

\section{Academic performance}

No differences were found for overall marks on either the module alone $(60.1 \%$ and $58.8 \%$ for $S$ and $E$ respectively, $t=0.29$, p-value $=.82$, two-tailed) or all modules combined (59.9\% and 58.9\% for $S$ and $E$ respectively, $t=-.885$, p-value $=.54$, twotailed). This supports Hypothesis 1 and suggests that greater efficiency need not compromise learning outcomes.

Module coursework consisted of a short essay on 'the aims and methods of literature review by constructive synthesis', a report on 'the aims, methods and results of a literature search, using university library on-line databases', a 6-minute oral presentation of a 'proposal for new empirical research' and a review by constructive synthesis of six specialist articles (introducing topics for further research training). In a 3-hour exam, students wrote a review by constructive critical synthesis of six speciallyprepared articles distributed twenty-four hours in advance.

The assessed oral presentations were video-recorded so that performance could be reviewed by academic assessors (the tutors of the module). The assessment criteria are summarised in the feedback form given to students, as shown in Table 2.

\section{Insert Table 2 about here}

Comparisons between the feedback regimes on module assessment are shown in Table 3 below. No significant differences between the feedback regimes were found for any assessed component of the module. 
Insert Table 3 about here

\section{Rating scale responses}

Regime differences in response styles were examined by comparing the distributions of the standard deviations of rating scale scores, shown in Figure 1. The regime standard deviations are not significantly different on average, with a Kruskal-Wallis test on the means of the distributions $1.225(S)$ and $1.190(E)($ chi-square $=0.567$, p-value $=.451)$ suggesting no difference in 'halo' effects. A Kolmogorov-Smirnov test suggests that the distributions are not significantly different ( $D$-statistic 0.2028 , p-value 0.244 ), so the rating scale analysis is assumed to be uncontaminated by regime differences in either extreme or central tendency responding.

\section{Insert Figure 1 about here}

Mean responses to the rating scale items are given in Table 4. The four pairs of items used to check response reliability are designated by ' $R$ ' in the table. Regime mean discrepancy scores were $2.36(S)$ and $2.46(E)$ and are not significantly different in a Kruskal-Wallis test (chi-square $=0.715$, p-value $=0398$ ). Of the eight respondents with discrepancy scores of 5 or over, four scored 5 and four scored between 6 and 8 . The results were therefore seen as reliable and all respondents were included in the analysis.

\section{Insert Table 4 about here}

Items 10 and 22 turned out to be ambiguously-worded. Item 10 points to two objects while item 22 could refer either to greater detail in verbal feedback or to more time for such feedback. Hence results for these two items must be interpreted with caution.

None of the regime differences even remotely approaches statistical significance, for any item. This strongly supports a conclusion that feedback methods could be made more efficient (less labour-intensive) without serious impact, either on how students perceive their effectiveness or on overall student satisfaction, so our remaining comments are restricted to ratings averaged across both regimes.

From items 1 to 4, it seems participants learned from their presentations and felt that their experience would both generalise to other situations and help with employability. However, they also claimed that watching other peoples' presentations was more effective than doing the presentations themselves. Two explanations seem possible. First, there is a difference between the action of presenting in a tutorial and the 
action of watching a presentation or reviewing it on video, so it is possible that the social aspect of the task focused students on performance rather than learning, and that they were responding to the emotional difference between high-anxiety (performance) and low-anxiety (observation) situations. Woodrow (2006), for example, provides evidence of performance anxiety in oral presentations by non-native language speakers - relevant here, since the majority of our students were Chinese. Second, this claim may have arisen because watching other people allowed students to form good benchmarks for comparison and improvement that they could apply when reviewing their own videos.

From items 5 to 8 it is evident that video feedback helped students to identify weaknesses in presentational style, although there is a suggestion that this was not sufficient alone and that effectiveness was enhanced by immediate verbal feedback.

Items 9 to 22 are concerned with verbal feedback. It appears that the participants valued verbal feedback highly, whether given to themselves or to others. Item 11 shows that immediate feedback was rated as preferable to delayed feedback, but with less strength than might have been expected. This is reflected in the open-ended responses (see below) where a minority would have preferred private one-to-one feedback (necessarily delayed). Interestingly, responses to item 22 (ambiguity notwithstanding) suggest that participants generally would have preferred to receive more feedback than they were given, even if they were already receiving extended feedback.

\section{Open-ended responses}

Results from three coded categories are reported here - 'Overall Evaluation', 'Overall Impact of Feedback' and 'Preferred Methods of Receiving Feedback'. The results are presented in Tables 5 to 7, in percentages of respondents. As noted above, a summary of aggregated responses in categories unrelated to feedback is reported in Leger and Sirichand (2015).

\section{Insert Table 5 about here}

Table 5 reveals that overall reaction to the module was strongly favourable for both regimes, but slightly less so for regime $S$, possibly because these students received a smaller amount of immediate verbal feedback (preferred by students in general). However, a Kolmogorov-Smirnov test showed that the regime distributions of mean 
responses to the elements for the 'Overall Evaluation' category were not significantly different ( $D$-statistic 0.400, p-value 0.810).

\section{Insert Table 6 about here}

The results in Table 6 for 'Overall Impact of Feedback' show fewer general positive responses and a greater number of specific responses in regime $S$ than in regime $E$. Any specific response was deemed to be positive unless otherwise stated and, since no respondent made an explicitly negative specific comment, all of the very few negative comments (4.3\% of respondents) are identified as general in nature. However, it can be seen, rather unexpectedly, that all come from regime $E$, where more feedback was given. There is no valid way to test the statistical significance of regime differences for individual elements, given the small numbers and lack of replication, so the regime distributions of the mean responses to all elements in this category were again compared using a Kolmogorov-Smirnov test. This found no significant effect ( $D$-Statistic 0.250, p-value 1.00) so the apparent regime differences in Table 6 may simply reflect normal sampling error.

The results in Table 7 appear to support the alternative to Hypothesis 2, that students in both regimes have an absolute preference for immediate verbal feedback. They also show that similar proportions of students (11\% in regime $S$ and $8 \%$ in $E$ ) preferred a feedback method that was not available ('paper/email/one-to-one'), which might reflect anxiety experienced by some people when receiving feedback in public.

Insert Table 7 about here

Table 7 hints at regime differences in the category 'Preferred Methods of Receiving Feedback'. A Kolmogorov-Smirnov test again shows no statistical significance for the difference in the distributions of mean responses ( $D$-statistic 0.3750 , p-value 0.66), but it is worth commenting on differences for individual elements.

First, it appears that more participants in regime $S$ preferred a combination of verbal and video feedback, while more participants in regime $E$ preferred either verbal or video feedback taken alone. Although video accessibility was equal across regimes it may be that interactions between verbal and video feedback can explain these results. We had no clear grounds for generating formal hypotheses about such interactions but, if anything, it was expected that regime $E$ would strengthen the preferences of students for verbal and video feedback taken together, relative to regime $S$, because extended 
verbal feedback should give more information about what to look for in the videos. However, students in regime $S$ actually show the stronger preference for 'verbal plus video'. A post-hoc explanation is that students in regime $S$ were forced to rely more heavily on video because they did not receive as much immediate feedback, leading to a greater appreciation of the combination and a stronger reported preference for it.

Second, the element 'Non-specific: give more feedback' suggests (weakly) that the desire for feedback increases with the amount actually given (10.4\% for regime $E$ compared to $2.2 \%$ for regime $S$ ). This reinforces the presumption that students place value on feedback generally but it also raises the possibility that demands for it might always be insatiable within resource constraints (that is, there may be no equilibrium).

\section{Conclusion}

This paper reports a comparison of two regimes in which feedback was given for oral presentations, in the context of training for literature review skills. The aims were to discover whether efficiency gains could be made in module delivery without compromising learning outcomes and to reveal student preferences for type of feedback.

A comparison of 'summary' and 'extended' verbal feedback regimes revealed no significant differences in either academic outcome or students' overall satisfaction with the module. The sample we used (45 to 48 participants in each regime) is not particularly small but we acknowledge that a larger sample might lead to statistically detectable differences. However there is very little in our results that cannot be easily explained by normal variation. Despite an absolute preference for verbal feedback over video, students in both regimes gave a strongly positive endorsement of the module.

These results provide a justification for using a more resource-efficient regime, with more presentations per tutorial and less time spent on immediate feedback, but they do not imply that immediate verbal feedback in skills training can be unconditionally reduced without consequence. It may seem unlikely, even incredible, that one minute of immediate verbal feedback could be highly effective, but the regimes used here included provision of online video as a complementary feedback method and we argue that very brief verbal feedback may be very informative in such circumstances. Hence there may be scope for both strengthening the role of video feedback in the type of skills training under review and examining in greater depth the relationships between verbal and video feedback. In particular, there could be a sharp 
reduction in skills acquisition if immediate verbal feedback were to be withdrawn altogether, and the impact of differential resource-use could be investigated by summary verbal feedback vs. no feedback. Such a comparison could be very interesting for further research.

One problem with providing feedback to students is that while they invariably ask for more of it in routine course evaluations they are also rather good at either ignoring or misunderstanding it, thus explaining the lack of significant regime differences in our results. However, while it is possible that our students may not have been paying attention to the feedback they were given and would have been unlikely to take advantage of more feedback had it been offered, we do not believe that this is so, for two reasons. First, feedback in our module is emphasised at every stage as a central part of an active learning process. Second, our students are acutely aware of the value of the module as preparation for employment or further study and have often reported in informal conversations that they pay very close attention to the feedback they are given. This is a major difference between this module and most others. This said, there is clearly scope for further research on student engagement with feedback.

Finally, the proportion (albeit fairly small) of students wanting one-to-one feedback suggests that students feel a significant degree of anxiety that could be worth further investigation with respect to module design. It is evidently necessary to be aware of, and possibly control, exposure to anxiety-provoking situations. However, students enrol in our degrees mainly with a view to obtaining employment and it seems appropriate to put them into situations that mimic public exposure. Informal discussions have shown very clearly that while they feel anxious when faced with oral presentations they also appreciate the opportunity to develop self-confidence and acquire important skills in the protective environment of the module, thereby equipping them for the more challenging and potentially more critical environment of the work-place and beyond. 


\section{References}

Leger, L. A and K. Sirichand. 2015. “Training for Literature Review and Associated Skills.” Journal of Applied Research in Higher Education 7 (2), 258-274.

Bandura, A. 1986. Social Foundation of Thought and Action: A Social Cognitive Theory. Englewood Cliffs, NJ: Prentice-Hall.

Beaumont, C., M. O'Doherty and L. Shannon. 2011. "Reconceptualising Assessment Feedback: a Key to Improving Student Learning?” Studies in Higher Education 36 (6), 671-687.

Biggs, J. and C. Tang. 2011. Teaching for Quality Learning at University. 4th ed. Maidenhead: Open University Press, McGraw-Hill.

Boud, D. and E. Molloy. 2013. "Rethinking Models of Feedback for Learning: The Challenge of Design.” Assessment \& Evaluation in Higher Education 38 (6), 698-712. Brockbank, A. and I. McGill. 2007. Facilitating Reflective Learning in Higher Education. 2nd ed. Maidenhead: McGraw-Hill, Society for Research into Higher Education and Open University Press.

Butler, D. L. and P. H. Winne. 1995, “Feedback and Self-Regulated Learning: A Theoretical Synthesis.” Review of Educational Research 65 (3): 245-281.

Carless, D., D. Salter, M. Yang and J. Lam. 2011. “Developing Sustainable Feedback.” Studies in Higher Education 36 (4): 395-407.

Cassidy, S. 2011. "Self-Regulated Learning in Higher Education: Identifying Key Component Processes.” Studies in Higher Education 36 (8): 989-1000.

Clark, I. 2012. “Formative Assessment: Assessment is for Self-Regulated Learning.” Educational Psychology Review 24 (2): 205-249.

Entwistle, N. J. and V. McCune. 2009. "The Disposition to Understand for Oneself at University and Beyond: Learning Processes, the Will to Learn, and Sensitivity to Context.” In Perspectives on the Nature of Intellectual Styles, edited by Zhang, L. F. and J. Sternberg, 29-62. New York: Springer.

Fukkink, R. G., N. Trienekens and L. J. C. Kramer. 2011. "Video Feedback in Education and Training: Putting Learning in the Picture.” Educational Psychology Review 23: 45-63. 
Garrison, D. R. and N. D. Vaughan. 2008. Blended Learning in Higher Education: Framework, Principles and Guidelines. San Francisco: John Wiley \& Sons.

Gibbs, G. and C. Simpson. 2004. “Conditions under which assessment supports students' learning.” Learning and Teaching in Higher Education 1 (1), 3-31.

Hattie, J. and H. Timperly. 2007. “The Power of Feedback.” Review of Educational Research 77 (1) 81-112.

Higgins, R., P. Hartley and A. Skelton. 2001. "Getting the Message Across: The Problem of Communicating Assessment Feedback.” Teaching in Higher Education 6 (2): 269-274.

Higgins, R., P. Hartley and A. Skelton. 2002. “The Conscientious Consumer: Reconsidering the Role of Assessment Feedback in Student Learning.” Studies in Higher Education 27 (1): 53-64.

Hoskins, S. L. and S. E. Newstead. 2009. “Encouraging Student Motivation.” In A Handbook for Teaching and Learning in Higher Education, Enhancing Academic Practice, 3rd ed., edited by H. Fry, S, Ketteridge and S. Marshall, 27-39. New York: Routledge.

Kolb, D. A. 1984. Experiential Learning: Experience as the Source of Learning and Development. Englewood Cliffs, NJ: Prentice Hall.

Machemer, P. L. and P. Crawford. 2007. "Student Perceptions of Active Learning in a Large Cross-Disciplinary Class-Room.” Active Learning in Higher Education 8 (2): 930.

Mager, R. F. 1991. Preparing Instructional Objectives. 2nd ed. London: Kogan Page.

McLeod, G. 2003. “Learning Theory and Instructional Design.” Learning Matters 2: 35-53.

Murphy, K. and Barry, S. 2015. "Feed-forward: students gaining more from assessment via deeper engagement in video-recorded presentations.” Assessment \& Evaluation in Higher Education, DOI: 10.1080/02602938.2014.996206.

Nicol, D. J. and D. Macfarlane-Dick. 2006. “Formative Assessment and Self-Regulated Learning: A Model and Seven Principles of Good Feedback Practice.” Studies in Higher Education 31 (2): 199-218. 
Njenga, J. K. and L. C. Fourie. 2010. “The Myths about E-Learning in Higher Education.” British Journal of Educational Technology 41 (2): 199-212.

Price, M., K. Handley, J. Millar and B. O’Donovan. 2010. “Feedback: All That Effort, but What is the Effect?” Assessment \& Evaluation in Higher Education 35 (2): 277-289. Ryan, R. M., and E. L. Deci. 2000. "Self-Determination Theory and the Facilitation of Intrinsic Motivation, Social Development, and Well-Being.” American Psychologist 55: $68-78$.

Sadler, D. R. 2010. “Beyond Feedback: Developing Student Capability in Complex Appraisal.” Assessment \& Evaluation in Higher Education 35 (5), 535-550.

Scaife, J. and J. Wellington. 2010. "Varying Perspectives and Practices in Formative and Diagnostic Assessment: A Case Study.” Journal of Education for Teaching 36 (2): 137-151.

Shute, V. J. 2008. “Focus on Formative Feedback.” Review of Educational Research 78 (1): 153-189.

Sloman, J. and C. Mitchell. 2013. “Lectures.” In The Handbook for Economics Lecturers, edited by P. Davies. The Economics Network, University of Bristol. www.economicsnetwork.ac.uk/handbook

Tennyson, R. D. 2010. “Historical Reflection on Learning Theories and Instructional Design.” Contemporary Educational Technology 1 (1): 1-16.

Zimmerman, B. J. 2005. “Attaining Self-Regulation: a Social Cognitive Perspective.” In Handbook of self-regulation, edited by M. Boekaerts, P. R. Pintrich and M. Zeidner, San Diego, 13-35. CA: Academic Press.

Zimmerman, B. J., and A. R. Moylan 2009. "Self-regulation: Where metacognition and motivation intersect.” In Handbook of Metacognition in Education, edited by D. J. Hacker, J. Dunlosky and A. C. Graesser, 299-316. New York: Routledge.

Zimmerman, B. J. and D. H. Schunk, eds. 2011. Handbook of Self-Regulation of Learning and Performance. Educational Psychology Handbook Series. New York: Routledge. 
Table 1. Tutorial Presentations - Schedule of Tasks, Reading Set 1: Ratings, Rankings and their Academic Impact'.

1. Present a 'bullet-point summary' of assigned articles.

2. Use a 'spider' to present a synthesis of themes arising from the articles.

These tasks specifically emphasise the processes of analysis and constructive synthesis that underlie literature review.

\begin{tabular}{|l|l|}
\hline $\begin{array}{l}\text { Tutorial 1: Presentation } \\
\text { (Time limit } 12 \text { minutes) }\end{array}$ & $\begin{array}{l}\text { Tutorial 2: Presentation } \\
\text { (Time limit 12 minutes) }\end{array}$ \\
\hline All Groups: Task 1 (selected articles) & All Groups: Task 2 (all articles) \\
\hline
\end{tabular}

\section{Reading Set 2: Ethics in Financial Markets}

1. Construct an outline literature review of all the articles in Set 2.

2. Use the articles in Set 2 to suggest and justify a new empirical investigation that would increase understanding of any issue concerning ethical standards in financial markets.

These tasks address the use of literature review in the research process.

\begin{tabular}{|l|l|}
\hline $\begin{array}{l}\text { Tutorial 3: Presentation } \\
\text { (Time limit } 12 \text { minutes) }\end{array}$ & $\begin{array}{l}\text { Tutorial 4: Presentation } \\
\text { (Time limit } 12 \text { minutes) }\end{array}$ \\
\hline All Groups: Task 1 & All Groups: Task 2 \\
\hline
\end{tabular}


Table 2. Coursework oral presentation - assessment criteria and feedback

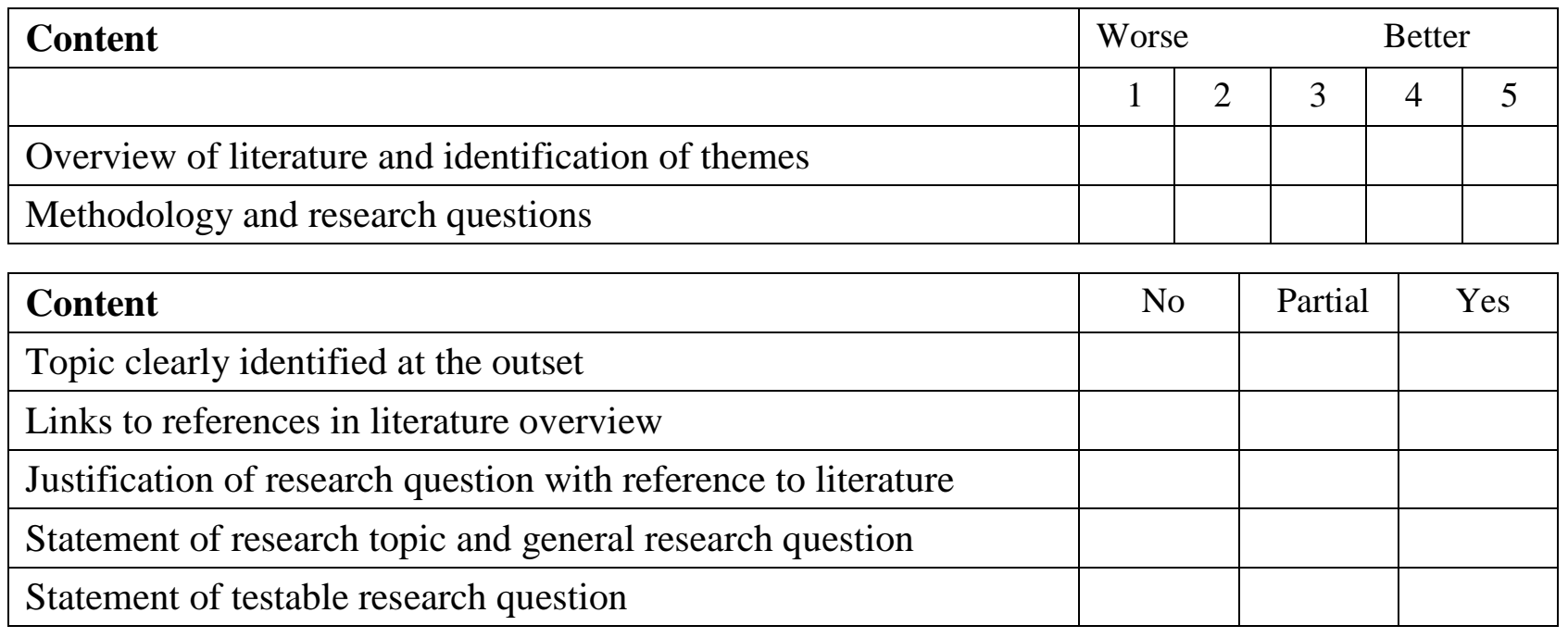

\begin{tabular}{|l|c|c|c|}
\hline Style & Poor & Fair & Good \\
\hline Focus on audience & & & \\
\hline Clarity and structure of oral presentation & & & \\
\hline Clarity of board presentation & & & \\
\hline
\end{tabular}

\begin{tabular}{|l|c|c|c|c|}
\hline Speed of presentation & Too slow & Too fast & Fair & Good \\
\hline
\end{tabular}

\begin{tabular}{|l|c|c|}
\hline Overall Task Achievement (these are examples only) & Mark guide & \\
\hline No research proposal attempted & $<40 \%$ & \\
\hline $\begin{array}{l}\text { Unclear whether new research was proposed } \\
\text { Policy prescription instead of research }\end{array}$ & $40-49 \%$ & \\
\hline $\begin{array}{l}\text { No proper justification with respect to the literature } \\
\text { Market research rather than scientific research }\end{array}$ & $50-59 \%$ & \\
\hline $\begin{array}{l}\text { Focused proposal with no cited references } \\
\text { Good references/review but poor methodology }\end{array}$ & $60-69 \%$ & \\
\hline Succinct focused proposal & $>69 \%$ & \\
\hline
\end{tabular}


Table 3. Regime differences in assessed module components (\% marks)

\begin{tabular}{|l|c|c|c|c|c|c|c|}
\hline $\begin{array}{c}\text { Assessed } \\
\text { Components }\end{array}$ & $\begin{array}{c}\text { CW (i) } \\
\text { (Aims) }\end{array}$ & $\begin{array}{c}\text { CW (ii) } \\
\text { (Search) }\end{array}$ & $\begin{array}{l}\text { CW (iii) } \\
\text { (Oral) }\end{array}$ & $\begin{array}{c}\text { CW (iv) } \\
\text { (Lit Rev) }\end{array}$ & $\begin{array}{c}\text { Total } \\
\text { CW }\end{array}$ & Exam & Overall \\
\hline$E$ & 61.25 & 58.02 & 56.88 & 58.02 & 58.44 & 59.17 & 58.80 \\
\hline$S$ & 62.81 & 58.23 & 59.27 & 61.04 & 58.49 & 59.73 & 60.10 \\
\hline t-value & 0.227 & 0.905 & 0.404 & 0.068 & 0.112 & 0.733 & 0.288 \\
\hline Significance & Non-sig & Non-sig & Non-sig & Non-sig & Non-sig & Non-sig & Non-sig \\
\hline
\end{tabular}


Table 4. Kruskal-Wallis test of regime differences in mean rating scale responses

\begin{tabular}{|c|c|c|c|c|c|}
\hline Item & & & $S$ & $E$ & $p$-value \\
\hline 1 & & $\begin{array}{l}\text { My experience in the Research Communication module has made me } \\
\text { more employable. }\end{array}$ & 3.82 & 3.77 & 0.94 \\
\hline 2 & & $\begin{array}{l}\text { My tutorial presentations have helped me prepare for making new } \\
\text { presentations in other situations. }\end{array}$ & 4.09 & 4.02 & 0.62 \\
\hline 3 & $R 1$ & $\begin{array}{l}\text { Watching other people make presentations was more effective in } \\
\text { helping me learn than doing tutorial presentations myself. }\end{array}$ & 3.60 & 3.52 & 0.64 \\
\hline 4 & & I learned nothing from making tutorial presentations. & 1.71 & 1.73 & 0.69 \\
\hline 5 & & $\begin{array}{l}\text { Video feedback was less helpful than immediate verbal feedback after } \\
\text { my tutorial presentations. }\end{array}$ & 2.76 & 2.81 & 0.86 \\
\hline 6 & & Video feedback alone would have been sufficient. & 2.31 & 2.56 & 0.20 \\
\hline 7 & & $\begin{array}{l}\text { Video feedback was only helpful because I had already received } \\
\text { immediate verbal feedback after my tutorial presentations }\end{array}$ & 3.09 & 3.14 & 0.74 \\
\hline 8 & & $\begin{array}{l}\text { Video feedback was important in helping me to identify things to } \\
\text { change in my presentation style. }\end{array}$ & 4.00 & 4.10 & 0.95 \\
\hline 9 & $R 2$ & $\begin{array}{l}\text { Immediate verbal feedback after my tutorial presentations was not } \\
\text { helpful. }\end{array}$ & 1.76 & 1.93 & 0.37 \\
\hline 10 & & Verbal feedback was painful but helpful. & 3.42 & 3.50 & 0.90 \\
\hline 11 & & $\begin{array}{l}\text { I prefer to have immediate rather than delayed verbal feedback after } \\
\text { my tutorial presentations. }\end{array}$ & 3.84 & 3.71 & 0.63 \\
\hline 12 & $R 3$ & $\begin{array}{l}\text { Making tutorial presentations was a sufficient learning experience - } \\
\text { further feedback was unnecessary to help me learn. }\end{array}$ & 2.23 & 2.33 & 0.73 \\
\hline 13 & & I learned nothing from watching other people's tutorial presentations. & 1.95 & 2.19 & 0.18 \\
\hline 14 & $R 4$ & $\begin{array}{l}\text { I would have been happy to receive less verbal feedback immediately } \\
\text { after my tutorial presentations. }\end{array}$ & 2.17 & 2.44 & 0.13 \\
\hline 15 & & $\begin{array}{l}\text { It was helpful to hear the verbal feedback given to other people's } \\
\text { presentations. }\end{array}$ & 4.11 & 3.98 & 0.67 \\
\hline 16 & & $\begin{array}{l}\text { The amount of verbal feedback I received after my tutorial } \\
\text { presentations was about right. }\end{array}$ & 3.78 & 3.73 & 0.89 \\
\hline 17 & $R 2$ & Immediate verbal feedback after my tutorial presentations was helpful. & 4.11 & 4.13 & 0.91 \\
\hline 18 & & $\begin{array}{l}\text { I felt uncomfortable when I was given immediate verbal feedback after } \\
\text { my tutorial presentations. }\end{array}$ & 1.87 & 2.08 & 0.23 \\
\hline 19 & $R 3$ & $\begin{array}{l}\text { The verbal and video feedback on my tutorial presentations added little } \\
\text { to what I learned from actually making the presentations. }\end{array}$ & 2.13 & 2.31 & 0.51 \\
\hline 20 & $R 1$ & $\begin{array}{l}\text { Watching other people make presentations was more effective in } \\
\text { helping me learn than doing tutorial presentations myself. }\end{array}$ & 2.91 & 3.00 & 0.67 \\
\hline 21 & & I learned nothing from making tutorial presentations. & 1.53 & 1.63 & 0.62 \\
\hline 22 & $R 4$ & $\begin{array}{l}\text { I would have preferred to receive more detailed verbal feedback } \\
\text { immediately after my tutorial presentations. }\end{array}$ & 3.96 & 3.94 & 0.81 \\
\hline
\end{tabular}

Strongly Disagree $=1$, Strongly Agree $=5, p$-value $<0.05$ required for significance.

Items marked $R$ (in numbered pairs) are used to calculate the discrepancy scores. 
Table 5. Overall evaluation

\begin{tabular}{|l|l|l|l|}
\hline Regime & $\boldsymbol{S}$ & $\boldsymbol{E}$ & $\boldsymbol{S}-\boldsymbol{E}$ \\
\hline & $\%$ & $\%$ & \\
\hline General comments positive & 66.6 & 77.0 & -10.4 \\
\hline Specific comments: positive & 15.6 & 14.6 & 1.0 \\
\hline Total positive comments & 82.2 & 91.6 & -9.4 \\
\hline General comments: negative & 0 & 2.1 & -2.1 \\
\hline Specific comments: negative & 8.9 & 4.2 & 4.7 \\
\hline Total negative comments & 8.9 & 6.3 & 2.6 \\
\hline Unclear or no response & 8.9 & 2.1 & 6.8 \\
\hline & 100 & 100 & \\
\hline
\end{tabular}


Table 6. Overall impact of feedback

\begin{tabular}{|l|l|l|l|}
\hline Regime & $\boldsymbol{S}$ & $\boldsymbol{E}$ & $\boldsymbol{S}-\boldsymbol{E}$ \\
\hline & $\%$ & $\%$ & \\
\hline General positive benefit & 42.2 & 66.6 & -24.4 \\
\hline Specific presentation effect* & 48.9 & 27.0 & 21.9 \\
\hline General negative effect (little or no feedback benefit) & 0 & 4.3 & -4.3 \\
\hline Unclear or no response & 8.9 & 2.1 & 6.8 \\
\hline & 100 & 100 & \\
\hline
\end{tabular}

* Specific impact of feedback covered communication with audience (eye contact, verbal interaction), oral speed and clarity, structure of whiteboard presentation and writing clarity. 
Table 7. Preferred methods of receiving feedback

\begin{tabular}{|l|l|l|l|}
\hline Regime & $\boldsymbol{S}$ & $\boldsymbol{E}$ & $\boldsymbol{S}-\boldsymbol{E}$ \\
\hline & $\%$ & $\%$ & \\
\hline Verbal & 42.2 & 50.0 & -7.8 \\
\hline Verbal plus video & 29 & 10.4 & 18.6 \\
\hline Video & 2.2 & 8.3 & -6.1 \\
\hline Paper/email/one-to-one & 11.1 & 8.3 & 2.8 \\
\hline Non-specific: give more feedback & 2.2 & 10.4 & -8.2 \\
\hline Feedback gained from observing other presentations & 0 & 4.2 & -4.2 \\
\hline Keep things as they are & 2.2 & 6.3 & -4.1 \\
\hline Unclear or no response & 11.1 & 2.1 & 9.0 \\
\hline & 100 & 100 & \\
\hline
\end{tabular}


Figure 1. Distributions of respondents' standard deviations of rating scores - regimes $S$ and $E$
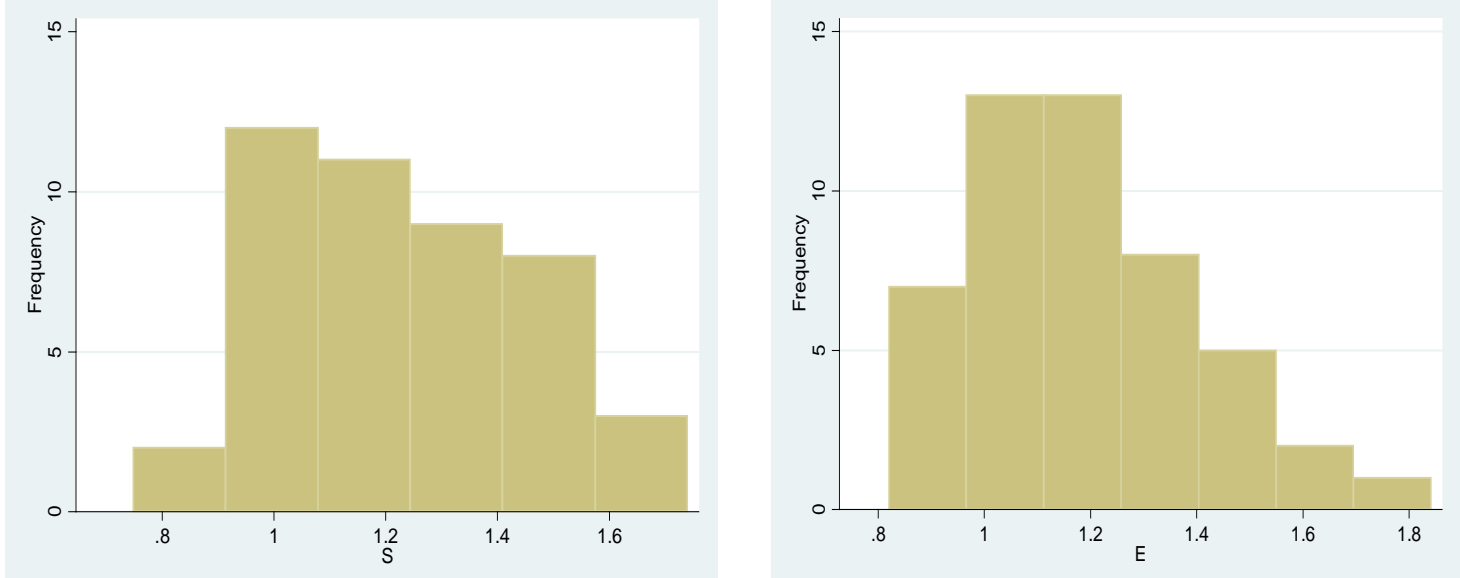